https://helda.helsinki.fi

\title{
Thermal behavior of green roofs under Nordic winter conditions
}

\section{Collins, Steven}

2017

Collins , S , Kuoppamäki , K , Kotze , D J \& Lü , X 2017 , ' Thermal behavior of green roofs under Nordic winter conditions ' , Building and Environment , vol. 122 , pp. 206-214 . https://doi.org/10.1016/j.builden

http://hdl.handle.net/10138/308075

https://doi.org/10.1016/j.buildenv.2017.06.020

cc_by_nc_nd

acceptedVersion

Downloaded from Helda, University of Helsinki institutional repository.

This is an electronic reprint of the original article.

This reprint may differ from the original in pagination and typographic detail.

Please cite the original version. 


\title{
1 THERMAL BEHAVIOR OF GREEN ROOFS UNDER NORDIC WINTER CONDITIONS
}

\author{
Collins, S..$^{\text {a* }}$, Kuoppamäki, K. ${ }^{\text {a }}$, Kotze, D.J. ${ }^{\mathrm{a}}$, Xiaoshu Lü ${ }^{\mathrm{b}}$
}

4

$5 \quad{ }^{a}$ Department of Environmental Sciences, University of Helsinki, Niemenkatu 73, FIN-15140 Lahti,

6 Finland

$7 \quad{ }^{b}$ Department of Engineering, Aalto University, PO Box 11000, FI-00076 Espoo, Finland

\section{Abstract}

11 To understand how green roofs affect building energy performance under cold climatic 12 conditions, a proper thermal analysis of the roof and its components is required. To address 13 this, we measured the thermal conductivity of each layer of experimental green roofs, as

14 well as the equivalent thermal resistance of the complete green roof system during winter 15 conditions in southern Finland. Green roofs were compared to bare roofs (without 16 substrate, vegetation and other green roof layers) to assess the basic functioning and 17 relative performance of the green roof system. Layer analysis at various intensities of frost 18 penetration showed that the thermal conductivity of each layer decreased when penetrated 19 by frost. In particular, thermal conductivity of the substrate and vegetation layers decreased 20 from $0.41 \mathrm{Wm}^{-1} \mathrm{~K}^{-1}$ and $0.34 \mathrm{Wm}^{-1} \mathrm{~K}^{-1}$ prior to freezing, to $0.12 \mathrm{Wm}^{-1} \mathrm{~K}^{-1}$ and $0.10 \mathrm{Wm}^{-1} \mathrm{~K}^{-}$

211 after freezing, respectively. This phenomenon is explained by a reduction in bridge-water 22 connectivity during freezing and a volumetric water content that was below the critical 23 threshold value. Overall, a frost depth that extended through the complete green roof 24 yielded the greatest equivalent thermal resistance at a mean value of $2.01 \mathrm{~m}^{2} \mathrm{WK}^{-1}$. During 25 times of snow cover, snow acted as an insulator and reduced the relative energy saving 26 benefits achieved by green roofs. These results provide information for designing the 27 substrate and vegetation layers of green roofs for optimal insulation.

29 Keywords: green roof, thermal conductivity, heat flux, energy saving, winter conditions 
32 Steven Collins

33 Present postal address: P.O.Box 12100, FI-00076 Aalto, FINLAND

34 E-mail: steven.2.collins@aalto.fi

35 Tel: +358 (0)503242410

36

37 E-mail addresses: steven.2.collins@ @alto.fi (S. Collins), kirsi.kuoppamaki@helsinki.fi

38 (K. Kuoppamäki), johan.kotze@helsinki.fi (D.J. Kotze), xiaoshu.lu@aalto.fi (Lü

39 Xiaoshu)

40

41 


\section{Introduction}

45 To make buildings more environmentally friendly, new energy efficient technologies and 46 designs are continually sought after. A green, or vegetated roof, is a structural design 47 approach that brings nature and engineering together to provide a sustainable alternative to 48 conventional roofing [1]. Among the multifunctional benefits that a green roof provides, 49 improved building envelope thermodynamics has been an important aspect for reducing 50 energy consumption within the building sector [2,3]. As a living system, a green roof's 51 thermal behavior is highly influenced by the surrounding climate. While it has been shown 52 that they are effective tools for reducing cooling energy demands in warm and sunny 53 climates [4-6], in cold climates, where heat energy demands dominate, there is still general 54 uncertainty and a lack of research about how beneficial a green roof may be [3].

56 Winter thermal benefits achieved from a green roof system depend on vegetation type and 57 material properties of the layers, including thickness, physical structure and thermal 58 conductivity [7-9]. Commonly, the layers of a green roof from the top down consist of 59 surface vegetation, substrate, filter/water retaining mat, drainage/root barrier, and a 60 waterproofing membrane that all sit atop the structural support. When necessary, green 61 roofs also utilize synthetic insulation at their base in order to ensure adequate thermal 62 resistance [10].

64 A green roof will keep itself, and the building below, cool in the summer by means of 65 evapotranspiration, photosynthesis and shading and yet remain an effective thermal mass 66 in winter when vegetation is dormant and evapotranspiration negligible [11]. In 67 comparison, an insulation system of only synthetic materials works well but is limited in 68 performance due to constant thermal properties throughout the year. The synthetic system 69 can thus only be optimized in terms of material thickness. Therefore, in designing for best 70 annual energy use, indoor thermal comfort, and sustainability, application of a vegetated 71 system in conjunction with minimal synthetic insulation, may provide the greatest thermal 72 performance for Nordic climates [6,11-13]. 
74 A modelling study on four different climates in the United States has shown that green

75 roofs have had greater heating energy savings in colder climates [14]. It has also been

76 shown that roof and wall vegetation could considerably reduce heat loss through the

77 building's façade in winter by reducing convective heat loss $[15,16]$. Thermal mass of the

78 green roof has been shown to reduce heat flux through the green roof during winter, by 1 -

$792 \mathrm{Wm}^{-2}$, and create more stable internal temperatures compared to a conventional roof

$80[17,18]$. Two studies conducted in the sub-tropical winters of Hong Kong have shown

81 beneficial results for an extensive green roof (traditionally defined as green roofs with

82 shallow substrates, see [19]) and negative results for an intensive green roof (with thicker

83 substrates [19]). In the case of the extensive roof, roofing materials acted as a heat sink that

84 released heat into the building during cooler nights [20]. In the case of the intensive roof,

85 heat was lost from the substrate to the air, drawing warmer indoor air outwards [21]. In the

86 French temperate climate, a green roof was shown to have very little impact on overall

87 heating demands due to reduced heat losses during cold winter days along with a reduction

88 in positive solar gains during sunny winter days [22]. Furthermore it was shown that snow

89 effectively insulates buildings but scales down the relative benefits that a green roof can

90 have compared to a conventional roof [2,23,24]. In the case of extreme weather conditions

91 with sub-zero temperatures and severe wind and rain, the benefits of green roofs tend to

92 increase [25], however, ice transfers heat energy more efficiently through its medium

93 compared to liquid water [26], suggesting greater heat loss for frozen green roofs. Overall,

94 given the variable performance in cold climates, a detailed understanding of energy loss

95 and heat flux through green roof systems is still required.

96

97 Currently, very few studies have examined the thermal behavior of green roof layers during

98 ice and snow conditions and none have exclusively evaluated overall or layer-specific

99 thermal conductivity (k-values, see [26]). Since the thermal properties of a green roof vary 100 significantly with moisture [7,27], and the thermal behavior of soil is affected by degree of 101 frost penetration [28-30], it is important to develop k-values for the green roof and its 102 component layers during winter conditions. Knowledge on the thermal behavior of the 103 individual layers during times of freezing and thawing and different levels of frost intensity 
104 would enable a better understanding of green roof thermal performance and resulting heat

105 flux under various winter conditions. A particular focus of this study is on the behavior of

106 the substrate layer because of its complexity for design applications and because there are

107 no current guidelines for the type of substrate to use for best thermal performance in

108 freezing conditions.

110 In this study we hypothesized that (i) frost penetration will increase green roof and green

111 roof layer k-values, (ii) substrate is expected to exhibit a positive relationship between

112 volumetric water content and $\mathrm{k}$-values above $0{ }^{\circ} \mathrm{C}$ and a positive relationship between frost

113 intensity and k-values below $0{ }^{\circ} \mathrm{C}$, (iii) heat flux through the green roof will be less than

114 the bare roof for the majority of the winter period, and (iv) snow cover will act as an

115 additional insulation layer, reducing heat flux through both roofing systems.

\section{2. Methods}

118

\subsection{Experimental setup}

121 The experiment was carried out at Jokimaa, a University of Helsinki research station 122 located in Lahti, southern Finland $\left(60^{\circ} 52^{\prime} \mathrm{N}, 25^{\circ} 52^{\prime} \mathrm{E}\right)$, where winter is the dominant 123 season, with long periods of sub-zero temperatures and snow cover that typically last 135124145 days [31].

126 Twenty-five roof platforms, each $1 \mathrm{~m} \times 2 \mathrm{~m}$ in size at a height of $1.5 \mathrm{~m}$ were constructed 127 at the station. Six of the platforms were used in this study (three green roofs and three bare 128 or control roofs) (Fig. 1). The base, or supporting layer, was a $24 \mathrm{~mm}$ thick hardwood 129 plywood. The bare roofs consisted only of the hardwood plywood support layer. For the 130 green roofs, directly atop the plywood was an "Antico Rankka" moisture barrier sheet 131 followed by a $25 \mathrm{~mm}$ thick water retaining and drainage layer made of molded polystyrene 132 ("Nophadrain" [32]), hereafter referred to as the "drainage" layer. On top of the drainage 133 layer was a $10 \mathrm{~mm}$ thick water holding filter fabric ("VT-filt": water storage capacity 81 $\left.134 \mathrm{~m}^{-2},[32]\right)$ used to prevent the loss of substrate particles and to retain water, hereafter 
135 referred to as the "fabric" layer. On top of these layers was a 50-60 mm thick substrate 136 layer made of crushed recycled brick (85\%), bark chippings (5\%), peat (5\%) and compost 137 (5\%; all percentages by fresh volume) (see Fig. 2 for particle size distribution).

138

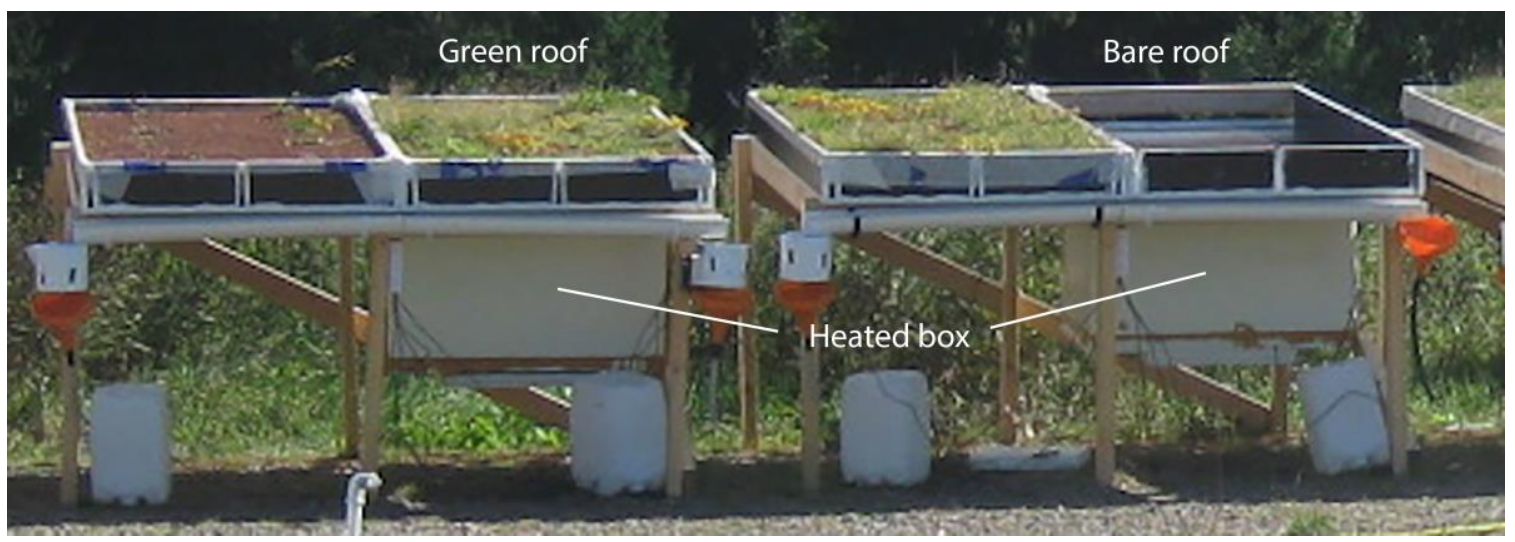

140
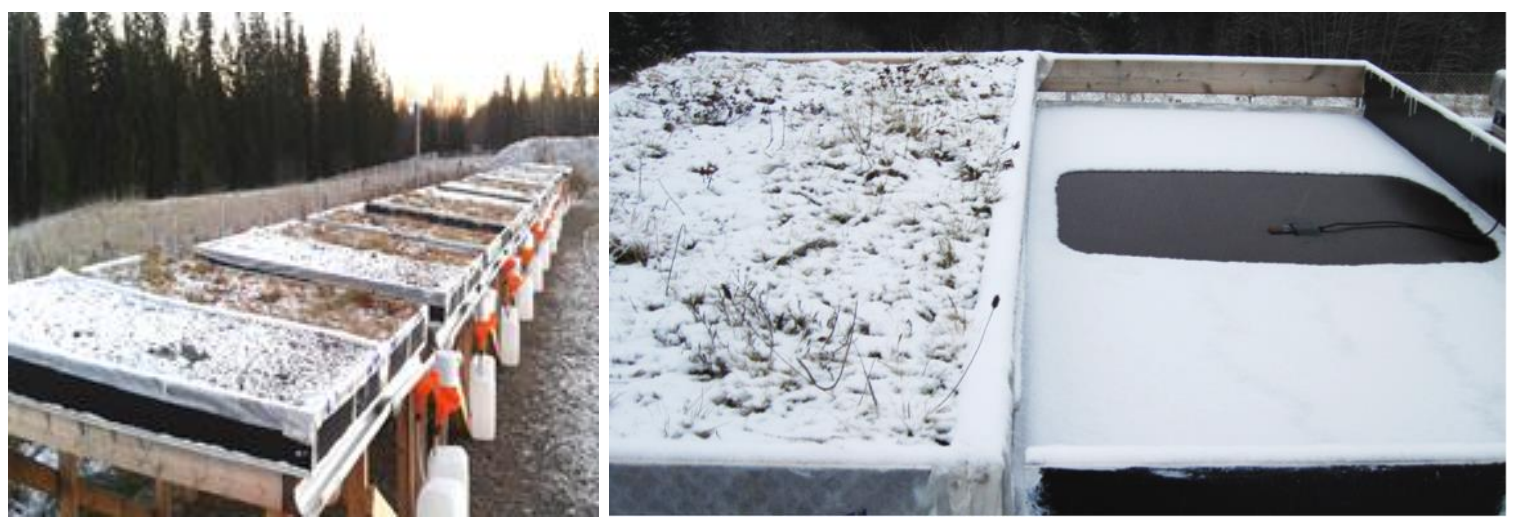


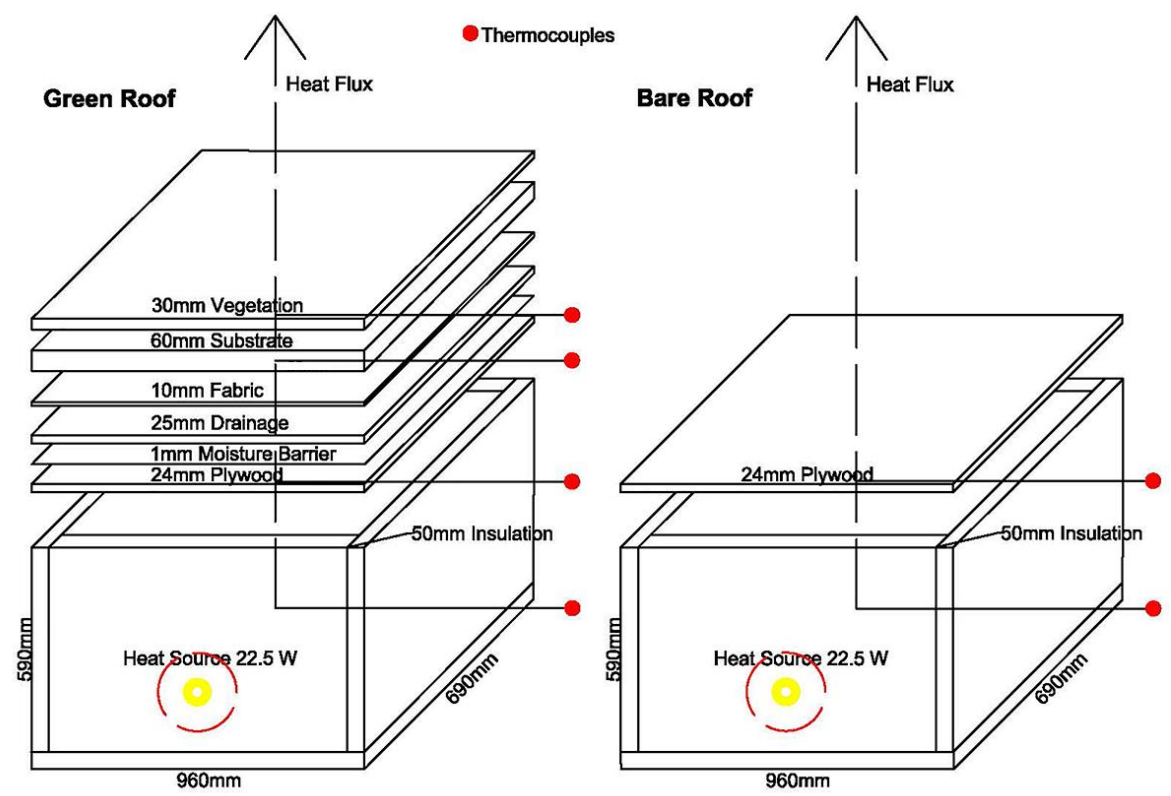

143 Fig. 1. Experimental green and bare roof setup (above) and schematic diagram of the 144 systems (below).

146 The top layer was a pre-grown vegetation "Veg Tech" mat with a nominal thickness of 40 $147 \mathrm{~mm}$ and supported drought resistant species of sedum, moss, and grass [32]. The dry 148 density of the substrate and vegetation layers was on average $1.37 \mathrm{~g} \mathrm{~cm}^{-3}$ and $1.17 \mathrm{~g} \mathrm{~cm}^{-3}$, 149 respectively. A closed $0.30 \mathrm{~m}^{3}$ (internal volume) insulated box was placed below each of 150 the six roofing structures. The box had five walls made of extruded polystyrene, a housing 151 insulation material ("Finnfoam 300/50") attached to the bottom surface of the plywood 152 layer. All boxes were equipped with identical heating sources: a $25 \mathrm{~W}$ incandescent light 153 bulb running at $90 \%$ inefficiency, 24 hours per day.

154

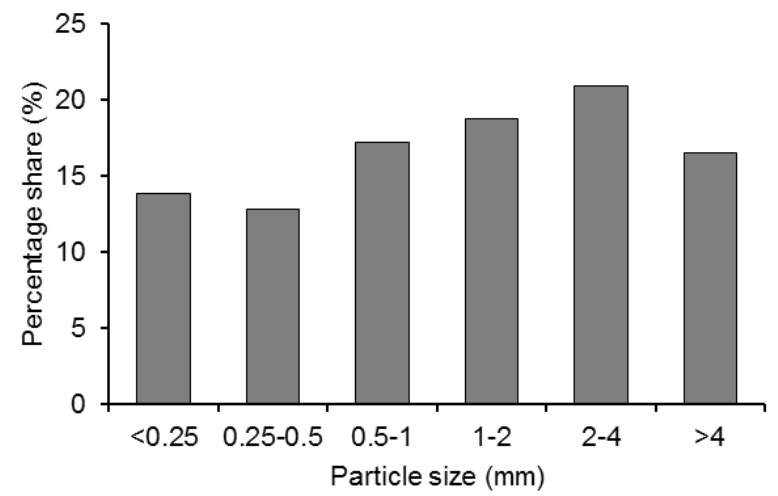


157 Fig. 2. The percentages of different sized particles in terms of dry weight for the crushed

158 brick mixture, used as substrate in the green roof platforms.

\subsection{Data collection}

162 For the green roofs, thermocouples with moisture sensors were placed on the vegetation

163 surfaces, within the substrates, on the top surface of the supporting structures (plywood),

164 and inside the insulated boxes. For the bare roofs, they were placed on the supporting 165 structures, and inside the insulated boxes (Fig. 1). Together the thermocouples were 166 arranged in a vertical line that passed through the centroid of the insulated box. 167 Temperature and moisture data were recorded at 20-min time intervals, $24 \mathrm{~h}$ per day at an 168 accuracy of $\pm 1{ }^{\circ} \mathrm{C}$ and $\pm 3 \%$ VWC [33]. VWC data were determined by measuring the 169 dielectric constant of the media using capacitance/frequency domain technology at $70 \mathrm{MHz}$ 170 frequency and are reliable only in soil [33]. Data loggers ("Decagon devices Em50") 171 collected the data. The on-site Vaisala WXT520 Micro Weather Station provided data on 172 ambient air temperature and precipitation, and recorded data at 10-min intervals. Snowfall 173 and snow depth information was obtained from the Finnish Meteorological Institute's

174 Laune weather station, located $5 \mathrm{~km}$ from the experimental site. The measurement period 175 for the roof ran from the beginning of October 2013 to the end of March 2014.

177 A linear one-dimensional temperature gradient was assumed in the vertical direction [34] 178 and when the temperature of the thermocouple decreased below zero degrees, it was 179 assumed that the layer and those above it, were penetrated by frost equal to the depth of 180 the thermocouple. When temperatures decreased further, it was assumed that frost was 181 penetrating further downward into the green roof. Since the fabric and drainage layer did 182 not have thermocouples within them, temperatures from the thermocouple on the plywood 183 surface were used to indicate that these bottom layers had frozen. All data were averaged 184 over the three replications. Means and standard deviations reported assume normally 185 distributed data. 
187 Temperature data were separated into phases determined by level of frost depth penetration

188 (Table 1). This was done in order to describe the effect of temperature on k-values during 189 various frost intensity levels.

190

191 Table 1. Description of each phase used in monitoring green roof thermal behavior.

\begin{tabular}{cll}
\hline Phase & Level of Frost Penetration & Details \\
\hline A & No frost penetration & $\begin{array}{l}\text { Pre-winter, positive ambient } \\
\text { temperatures, no snow. }\end{array}$ \\
\hline \multirow{2}{*}{ B } & No frost penetration & $\begin{array}{l}\text { Thawing, positive ambient } \\
\text { temperatures, snow on roof. }\end{array}$ \\
\hline \multirow{2}{*}{ C } & Frost penetration into vegetation & Light sub-zero ambient \\
& layer only & temperatures. \\
\hline \multirow{2}{*}{ D } & Frost penetration into vegetation & Sub-zero ambient \\
& and substrate layers only. & temperatures. \\
\hline \multirow{2}{*}{ E } & Frost penetration into all layers. & Intensive sub-zero ambient \\
& & temperatures. \\
\hline
\end{tabular}

192

193

\subsection{Theoretical approach}

195 Heat transfer through the green roof is a transient process, however, because the aim of

196 this study was to asses the thermal behavior of a green roof in cold climate, a steady state

197 analysis was assumed to quantify heat flux. The steady state approach provides a

198 quantitative estimate of $\mathrm{k}$ and $\mathrm{R}$-values that are useful as a reference for qualitative

199 interpretation of the thermal behaviour of the geen roof and its compnent layers [7].

201 A probilistic analysis on large samples of temperatures recorded provide most likely $\mathrm{k}$

202 and R-values and associated variance during each phase of frost penetration. 
$208 Q_{\text {roof }}=Q_{\text {source }}-Q_{\text {walls }}$,

210 where $\mathrm{Q}_{\text {roof }}$ is the overall heat flux through the bare or green roof surface, $\mathrm{Q}_{\text {source }}$ is the

211 energy input from the incandescent light bulb, and $\mathrm{Q}_{\text {walls }}$ represents heat flux through the

212 insulated walls of the heated box.

214 During winter, there is a temperature gradient through the roofing components of both the

215 bare and green roofs due to the temperature difference between the warm inside air and the

216 cold outside air. The majority of heat transferred from the interior outward in a green roof

217 is through conduction $[2,10]$. Integrating Fourier's equation for steady state heat transfer,

218 over the thickness of a medium, the mathematical model for heat flow by conduction is

219 expressed as:

220

221

$Q / A=T_{1}-T_{2} /(L / k)$

223 where $A$ is surface area through which heat flux occurs $\left(\mathrm{m}^{2}\right) ; L$ is roof medium thickness

$224(\mathrm{~m}) ; \mathrm{T}_{1}$ and $\mathrm{T}_{2}$ are vertical temperature points $(\mathrm{K}), k$ is thermal conductivity $\left(\mathrm{Wm}^{-1} \mathrm{~K}^{-1}\right)$, 225 and $L / k$ is thermal resistance (R-values) for conduction $\left(\mathrm{m}^{2} \mathrm{KW}^{-1}\right)$.

227 In locations where the temperature was not given by a thermocouple (interface of the 228 vegetation and substrate layer, interface of the fabric and substrate layer, and the outside 229 surface of the insulated box) an interpolated value was obtained by simultaneously solving 230 for the k-values and heat flux of the corresponding layers.

\subsection{Invariant thermal properties}

234 Thermal conductivity and resistance of the insulating material (used for the heated boxes) 235 and the plywood base are assumed constant throughout the experiment (Table 2). The 236 thermal properties of these materials are a function of humidity and temperature, however 
237 at normal ambient temperatures any change is negligible in comparison to the other roofing 238 components [35,36].

240 Table 2. Thermal resistance $(\mathrm{R})$ and thermal conductivity $(\mathrm{k})$ of materials used for both the 241 green and bare roofs. Plywood R and k uncertainty $=10 \%$. Thermal Resistance Thermal Conductivity

\begin{tabular}{lcc} 
& $\left(\mathrm{m}^{2} \mathrm{KW}^{-1}\right)$ & $\left(\mathrm{Wm}^{-1} \mathrm{~K}^{-1}\right)$ \\
\hline Plywood $(24 \mathrm{~mm})$ & 0.27 & 0.09 \\
Box insulation $(50 \mathrm{~mm})$ & 1.45 & 0.035 \\
\hline
\end{tabular}

\section{3. Results and Discussion}

\subsection{Green roof thermal conductivity}

247 Green roofs resisted heat loss better than the bare roofs during all frost depth phases.

248 Analysis of the various green roof layers show that k-values of the vegetation and substrate

249 layers decreased as frost penetration depth increased (Fig. 3). Since the k-value of ice is 250 about 4 times higher than water $\left(\mathrm{k}_{\text {water }}=0.60 \mathrm{~W} \mathrm{~m}^{-1} \mathrm{~K}^{-1}, \mathrm{k}_{\text {ice }}=2.30 \mathrm{~W} \mathrm{~m}^{-1} \mathrm{~K}^{-1}\right) \mathrm{a}$ 251 corresponding increase in green roof layer k-values were expected during freezing, 252 however, the opposite was observed. Correspondingly, green roof equivalent R-values 253 increased as frost penetration depth increased, indicating that green roofs were better 254 insulators during colder temperatures. 


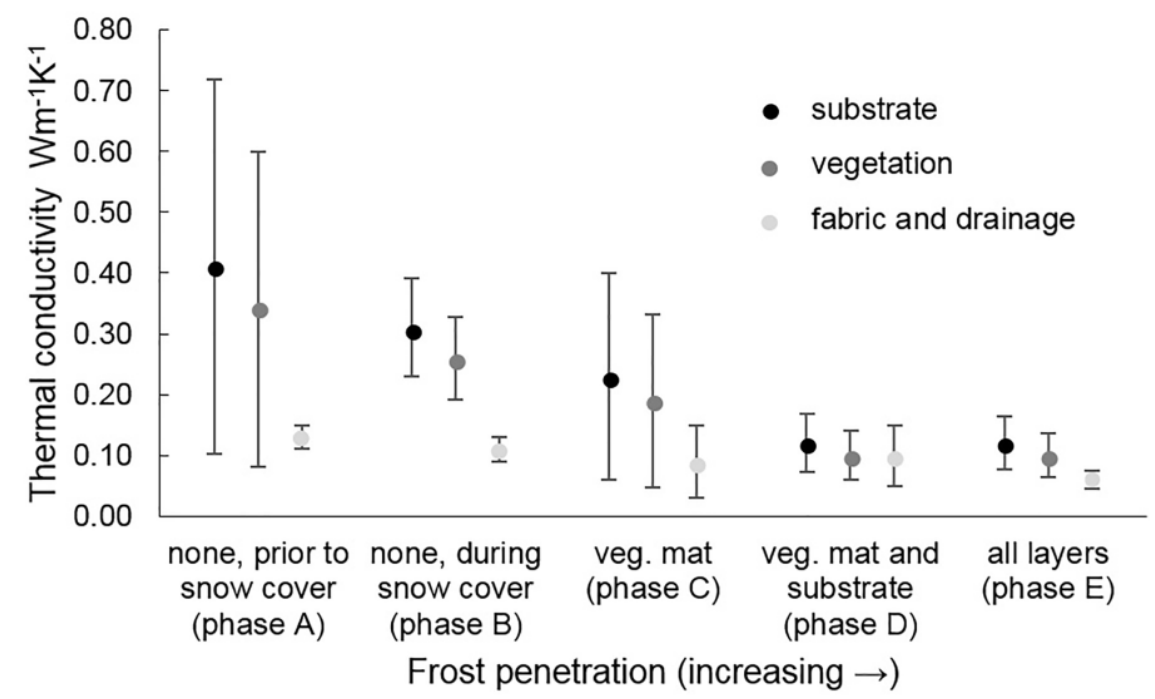

258

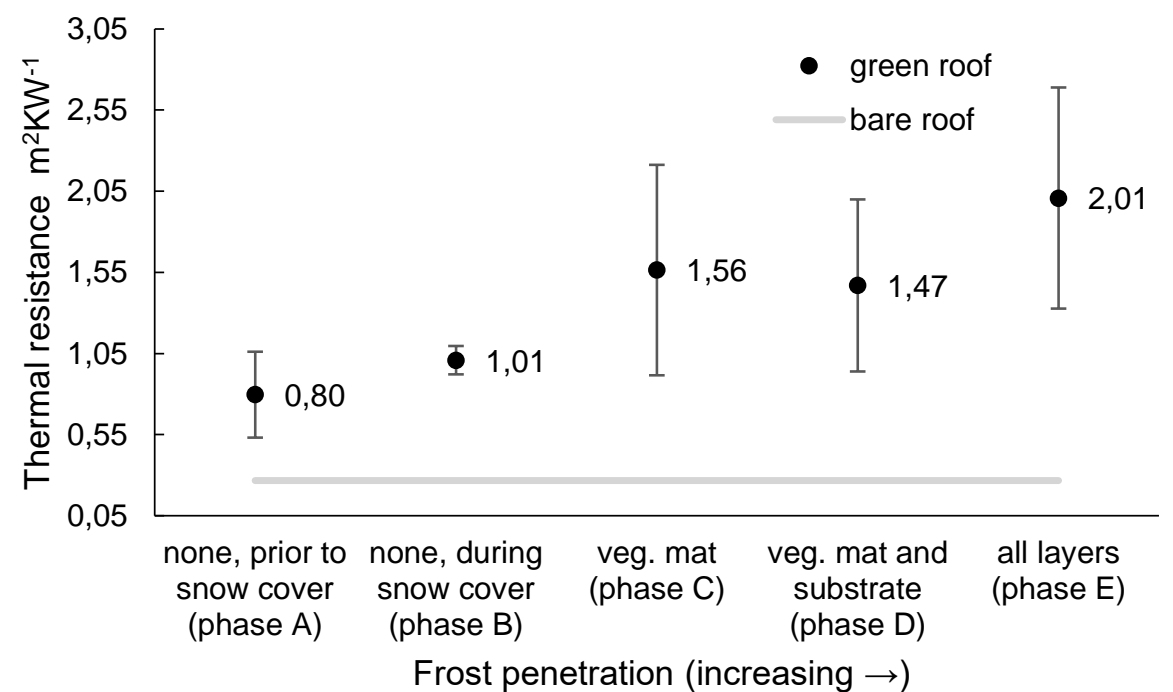

260 Fig. 3. Mean ( \pm SD) thermal conductivity (k-value) of green roof layers (above) and 261 equivalent thermal resistance (R-value) of green and bare roofs (below) during the different phases of frost penetration. Averaging time for each phase was 8-10 days.

264 During all phases of frost penetration, the substrate layer maintained the highest k-values

265 with the vegetation mat having predominately the second highest values, slightly below

266 those of the substrate. The fabric/drainage layer resisted heat flow the most, and its k-values

267 remained relatively consistent throughout the winter season. Insulation properties of the

268 fabric and drainage layers may be due to the large volume of stationary air held within the

269 drainage structure [37].

270

271 Variation in k-values shows how vulnerable green roofs are to surrounding environmental 
272 conditions (see SDs in Fig. 3). However, variability was lower during snow cover on these

273 roofs. In the case of no snow cover prior to frost penetration (phase A), variability of both

274 the vegetation and the substrate was high, with a coefficient of variation (CV) of 0.76 and

2750.75 , respectively. High variation was also present during phase $C$, when there was frost

276 penetration only into the vegetation layer (CV for the vegetation and substrate layers were

2770.75 and 0.74 , respectively). Variation is greatly reduced during the other phases,

278 especially when all the green roof layers had frozen (phase E) with a CV of $0.36,0.36$, and

2790.24 for the vegetation, substrate, and fabric and drainage layers, respectively.

281 A mean $\mathrm{R}$-value of $2.01 \mathrm{~m}^{2} \mathrm{~K} \mathrm{~W}^{-1}$ achieved by the green roof, when all the layers were

282 frozen, indicates that the system, while not as effective as synthetic insulation, has 283 performed reasonably well as a thermal insulator during extreme winter conditions.

284 Moreover, the reduction in k-values with decreasing sub-zero temperatures demonstrate a

285 positive dynamic behavior that improves its thermal resistance, as higher values of 286 resistance are desired.

288 It should be noted that green roof $\mathrm{k}$ and $\mathrm{R}$-values are based on a simplified steady state 289 analysis and the estimated values are more important for analysis of behavioral trends and 290 relative performance rather than value accuracy.

\subsection{The effect of volumetric water content on substrate thermal conductivity}

294 The decrease in substrate and vegetation k-values during freezing may be explained by

295 VWC and structural changes that occur within the layers when water turns into ice. In this

296 study, only the substrate layer VWC was measured and an explanation on micro scale 297 effects are discussed in relation to those measurements. VWC and corresponding k-values 298 of the substrate layer throughout winter are shown in Fig. 4.

300 Prior to freezing (mid-October - late-November), VWC of the substrate had values

301 fluctuating around $0.20 \mathrm{~m}^{3} \mathrm{~m}^{-3}$. This period had $\mathrm{k}$-values corresponding to phase A. During 302 times of thawing with snow cover (late-December and mid-February) substrate VWC was 
303 lower than it was prior to freezing despite the melting snow above the substrate. This period

304 has k-values corresponding to phase B.

305

306 The first cold period began in November (24.11.2013) and ended in the beginning of

307 December (05.12.2013). During this period, VWC decreased from $0.20 \mathrm{~m}^{3} \mathrm{~m}^{-3}$ to $0.06 \mathrm{~m}^{3}$

$308 \mathrm{~m}^{-3}$ indicating liquid moisture reduction due to frost penetration. This period had $\mathrm{k}$-values

309 corresponding to phase $\mathrm{C}$.

310

311 Phase E was experienced in January when temperatures decreased well below $0{ }^{\circ} \mathrm{C}$, to 312 minimum values of $-20^{\circ} \mathrm{C}$. During this period, substrate VWC also reached its lowest point

$313\left(0.02 \mathrm{~m}^{3} \mathrm{~m}^{-3}\right)$, indicating that practically all the water in the substrate had frozen.

315

316

317

318

319

320

321

322

323

324

325
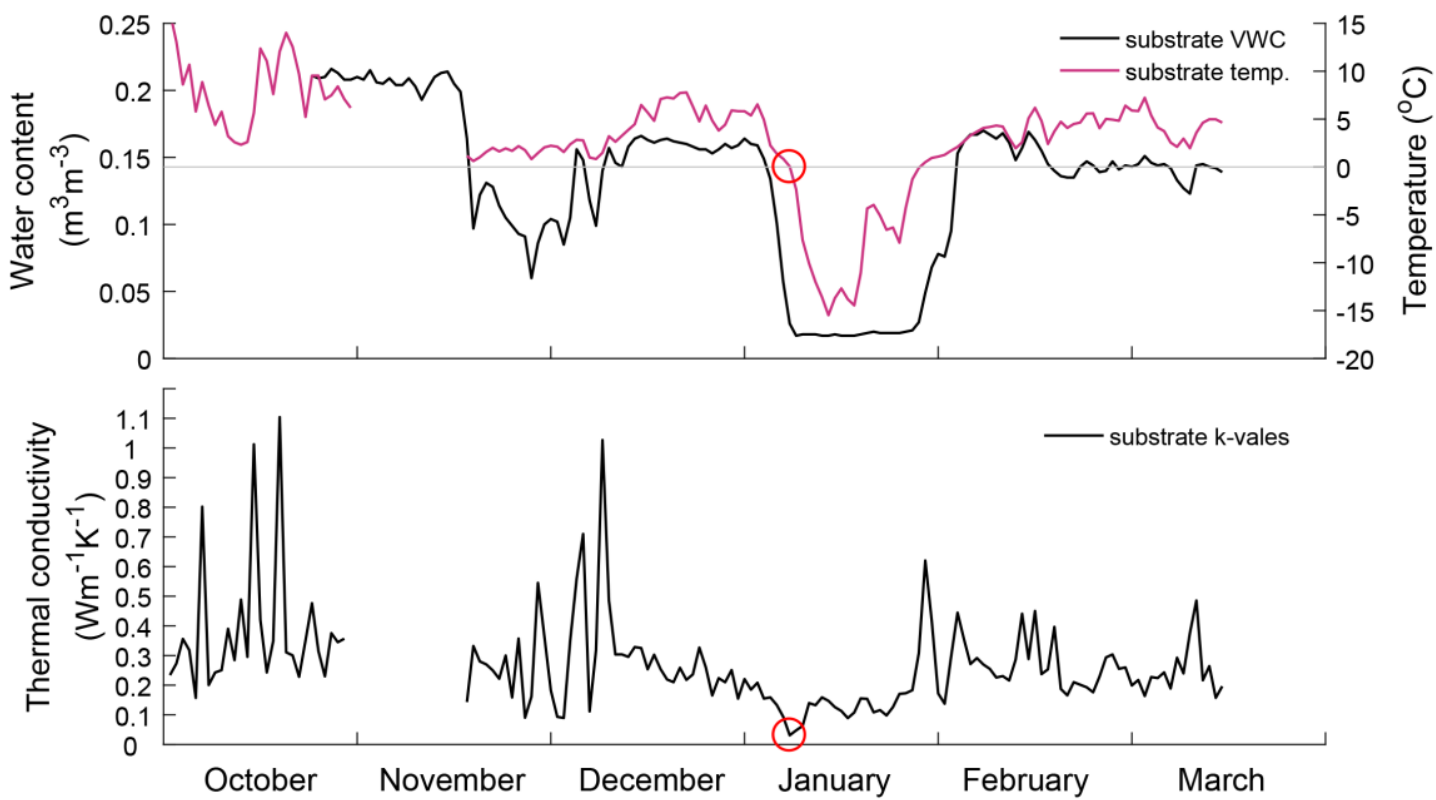

Fig. 4. Daily mean volumetric water content and temperature of the substrate layer at a depth of $5 \mathrm{~cm}$ (i.e. in the middle of the substrate) (above). Daily mean thermal conductivity of the substrate layer (below). The circles indicate initial frost penetration into the substrate layer. Missing information in the figures is due to one or more of the heat sources temporarily malfunctioning.

With increasing frost penetration, average substrate $\mathrm{k}$-values decreased from $0.41 \mathrm{~W} \mathrm{~m}^{-1}$ $\mathrm{K}^{-1}$ in unfrozen conditions, to $0.23 \mathrm{~W} \mathrm{~m}^{-1} \mathrm{~K}^{-1}$ as frost started to penetrate the substrate layer. Finally, average k-value reduced to $0.12 \mathrm{~W} \mathrm{~m}^{-1} \mathrm{~K}^{-1}$ when frost had fully penetrated the 
326 layer. The reduction in k-values indicated that freezing of the substrate layer improved its 327 insulative capacity, despite the higher k-value of ice. Furthermore, an immediate reduction 328 in substrate k-values was observed during initial freezing of the layer (Fig. 5).

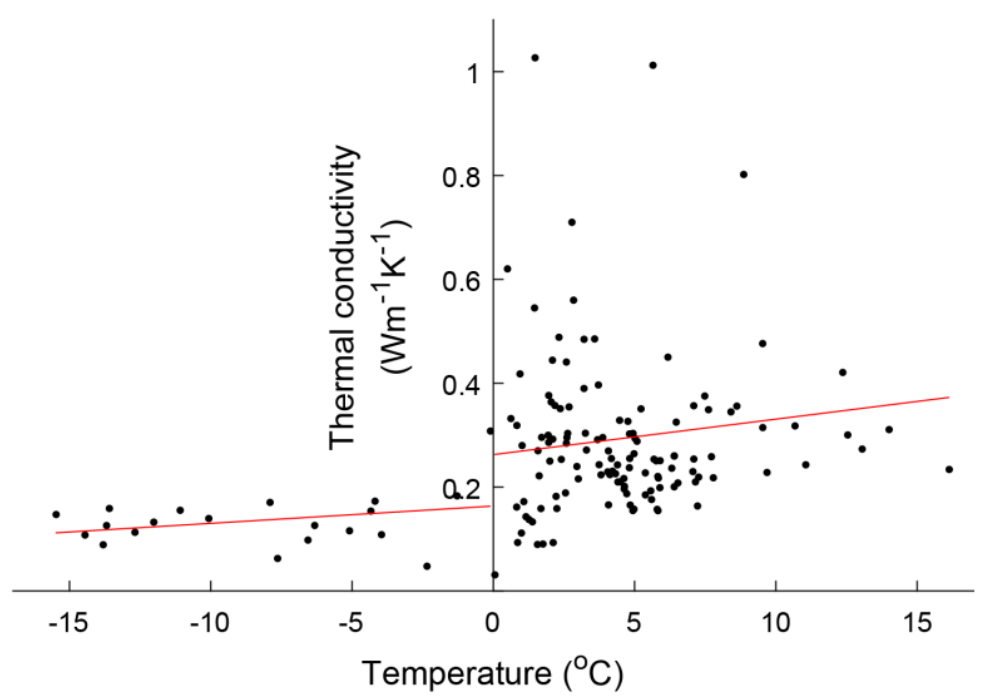

334 The different behavior of $k$-values before and after freezing may be explained by the bridge 335 water effect at positive temperatures and particle discontinuity at negative temperatures. 336 The basic features of these phenomena in freezing soils are explained in [28,38]. At 337 temperatures above zero, the positive correlation between k-values and soil water content 338 is due to the relative $\mathrm{k}$-values of water and air $\left(\mathrm{k}_{\text {water }}=0.60 \mathrm{Wm}^{-1} \mathrm{~K}^{-1}, \mathrm{k}_{\text {air }}=0.024 \mathrm{Wm}^{-1} \mathrm{~K}^{-}\right.$

$339^{1}$ ). With increasing VWC, pore space within the soil is replaced with water and heat is then 340 transferred through water, connected soil particles, as well as the additionally connected 341 soil structure created by the water-to-soil bridging. Water that covers and lines the solid 342 particles of the soil creates new points of connectivity between the particles, increasing the 343 effective surface area available for heat transfer [28]. This is known as the bridge water 344 effect and may explain the positive relationship between k-values and VWC observed at 345 positive temperatures. Furthermore, since water in the green roof is dynamic [39], changes 346 in particle connectivity would also be dynamic, explaining the large dispersion of k-values $347(\mathrm{CV}=0.75)$ observed during the unfrozen phases in Fig. 3. The positive correlation 
348 between substrate water content and k-values during warm conditions is in agreement with

349 other green roof studies, e.g. [8,27].

351 At sub-zero temperatures, substrates can exhibit a reduction in k-values during freezing

352 given the VWC is low enough. This phenomenon may occur due to a loss of connectivity

353 within the layer as water molecules reform to create solid ice. The contact points and bridge

354 water that existed in liquid form at positive temperatures are lost as solid ice crystals form.

355 During this transformation, ice $\mathrm{H}-\mathrm{O}-\mathrm{H}$ molecules move inward and away from the substrate 356 particles breaking connection points throughout the layer [40,41]. This disconnection

357 within the substrate continues to develop as temperatures decline and more ice forms. The

358 available surface area in which conductive heat transfer can occur is thus decreased and 359 the substrate layer becomes a less efficient heat transfer medium [28]. Furthermore, the

360 fusion process of water causes expansion and this may also result in substrate particle

361 disconnection and increased void space as the heaving material moves outward. This 362 phenomenon may explain the observed decrease in k-values for both the substrate and 363 vegetation in our study (Fig. 3). The declining efficiency of heat transfer observed during 364 decreasing temperatures was similar to various soils tested in [42] and [28]. Conversely, 365 soils tested in [43] note a considerable increase in soil k-values during freezing and relate 366 it to an extensive ice build-up (i.e. high VWC). A study that measured the k-values of 367 frozen soils during phase transition reported an immediate increase in k-values at the point

368 of freezing followed by an exponential decrease of k-values as temperatures continued to 369 decrease [44]. Therefore, both increases and decreases in soil k-values are possible during 370 freezing [28].

\subsection{Critical moisture content}

373

374 Theory suggests that there is a threshold VWC that causes soil k-values to increase or 375 decrease during a phase change. It has been shown in various soils of various properties 376 and aggregate size [30,40]. The relationship is not valid for every soil type but has been

377 shown to hold true for several types, including coarse-sandy soils [40], thus corresponding 378 to the rather coarse crushed brick substrate used in our study (Fig. 2). According to [28], 
379 when VWC is below a certain critical moisture content, the k-value of a freezing soil 380 decreases when temperature is reduced and if it is above the critical VWC, an increase in

381 k-values occur. In [30], the threshold moisture content was shown to be $15-20 \%$ for the 382 soil studied. The soil studied in [29] had a relatively high moisture content (45\%) and

383 reported a 50\% increase in winter k-values compared to summer ones. In our study, a 384 decrease in substrate k-values was achieved during the freezing periods (Fig. 4), suggesting 385 the VWC of the green roofs was below the critical moisture content. Prior to the November 386 freezing period, VWC was $20 \%$ and in January it was, $15 \%$.

388 The vegetation mat acted similar to the substrate layer and a reduction in k-values with 389 decreasing temperatures was achieved as well (Fig. 3). With increasing frost penetration, 390 average vegetation $\mathrm{k}$-values decreased from $0.34 \mathrm{~W} \mathrm{~m}^{-1} \mathrm{~K}^{-1}$ in unfrozen conditions to 0.10

$391 \mathrm{~W} \mathrm{~m}^{-1} \mathrm{~K}^{-1}$ when frost had fully penetrated the layer. The reasons for this may be the same 392 as the substrate layer; however, VWC was not measured in the vegetation layer. Overall, 393 the vegetation layer consistently acted as a better insulator than the substrate layer. This 394 may be due to higher density of the substrate since a denser medium increases heat transfer 395 efficiency, maintains unfrozen water longer and reduces permeability [28].

397 The importance of soil density on heat transfer was examined in [45] where it was observed 398 that the k-values of a frozen soil, at negative temperatures, decreased with increasing 399 temperature gradients and at positive temperatures, increased with increasing temperature 400 gradients. However, since the density of the frozen soil was very low $\left(0.81 \mathrm{~g} \mathrm{~cm}^{-3}\right)$ and the 401 top soil had a lower temperature than the lower soil, convective heat transfer occurred 402 causing the k-values of the frozen soil to be five times higher than k-values at positive 403 temperatures. Therefore, determination of the critical moisture content for vegetation and 404 substrate layers is crucial for green roof designs in Nordic climates, as long as conductive 405 heat transfer is the dominating form of heat loss. 
409 During winter, the green roof performed consistently better than the bare roof in terms of

410 heat flux. Due to additional thermal mass, the green roof had significantly less heat flux 411 through the roofing system (paired $t$-test, $t=1.731, p=0.043$ ) most of the time, and less 412 heat flux throughout the winter period (Fig. 6).

413

414

415

416

417

418

419

420

421 During the major freezing period in January 2014, there was an initial decrease in heat flux

422 for the green roof (see arrow in Fig. 6). This happened when the vegetation and substrate

423 layers were freezing and shows the strong effect of phase change on overall heat loss.

424 However, the continuous decrease in temperatures was not accompanied by a continuous

425 decrease in heat flux. This may be because snow had begun to accumulate on the green

426 roofs, altering the overall heat flux of the roofs.
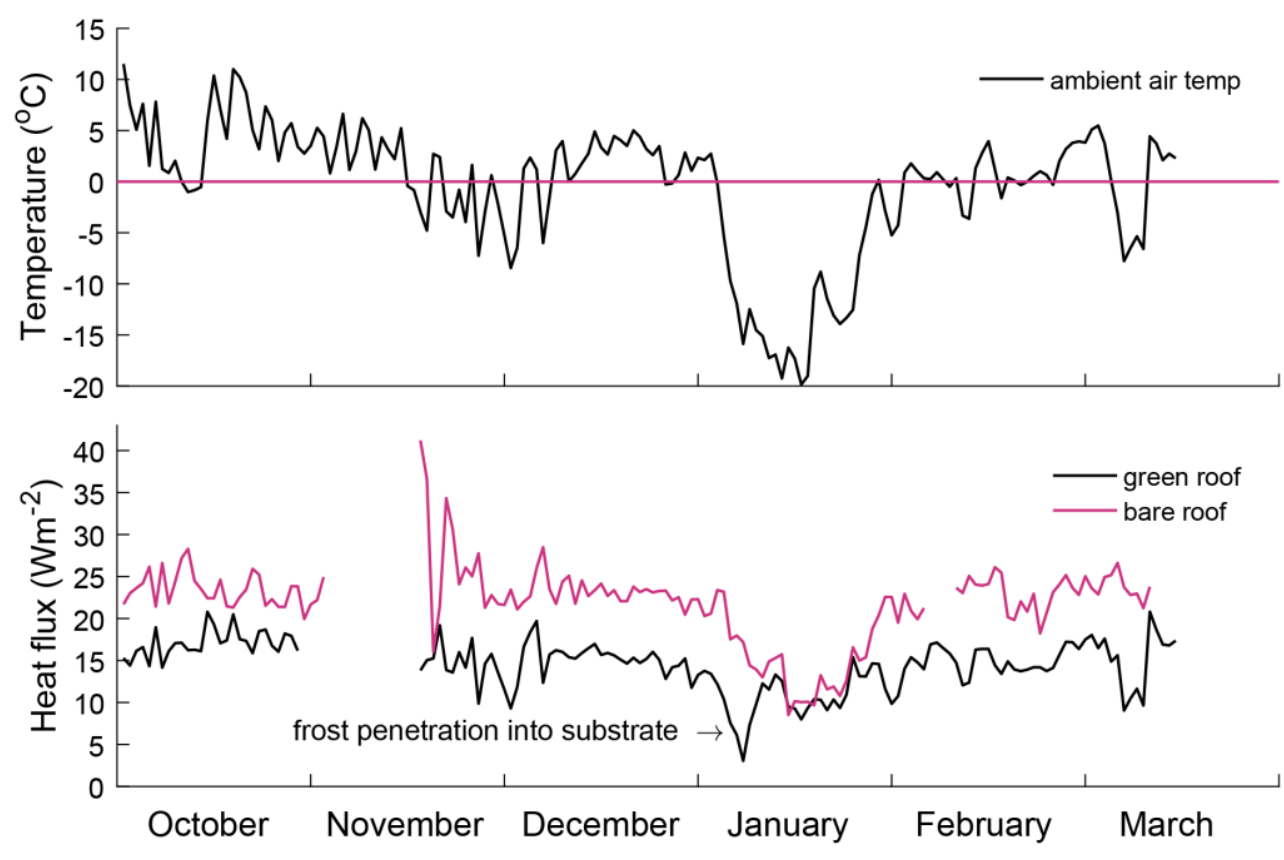

Fig. 6. Daily mean air temperature (above) and daily mean heat flux through bare and green roofs (below) during the winter of 2013-2014. Positive heat flux values indicate heat transfer from inside to outside through the roofs. The arrow indicates when frost penetration reached the mid-point of the substrate layer.

The largest difference in heat flux between the bare and green roofs occurred when ambient air temperatures were oscillating around $0{ }^{\circ} \mathrm{C}$. This freeze-thaw period occurred at the end of November and the beginning of December 2013 when the green and bare roof heat flux 
431 had greater fluctuations compared to other winter periods (Fig. 6). Sudden and large 432 reductions in green roof heat flux were observed during periods when ambient 433 temperatures decreased below $0{ }^{\circ} \mathrm{C}$ and frost penetration into the vegetation layer led to 434 immediate reductions in k-values.

436 Mean daily energy loss was equated from mean daily heat flux in order to compare the 437 monthly reduction in heat loss achieved by the green roof. The addition of the green roof 438 saved a significant amount of energy each month throughout winter, compared to the bare 439 roof (paired $t$-test: $t=5.593, p=0.001$; Fig. 7).
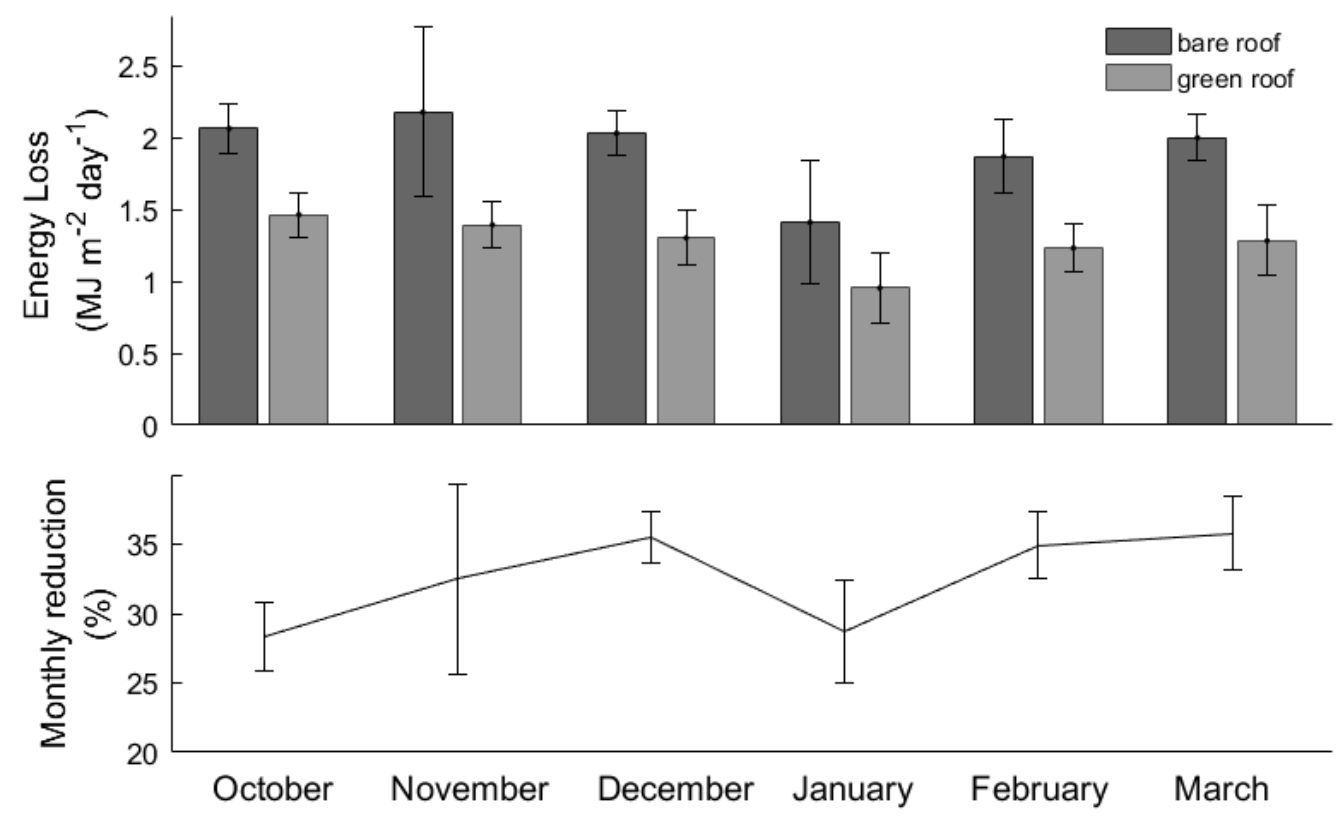

441 Fig. 7. Daily mean ( \pm SD) energy loss through the bare and green roofs (above) and daily 442 443

445 Overall, December 2013 and March 2014 were two months with the greatest reduction in 446 heat loss. December achieved lower heat losses because of reduced temperature 447 fluctuations and reduced $\mathrm{k}$-values in the vegetation layer. The results during November and 448 March may have occurred for the same reason as December. However, only partial monthly 449 data were available for these months. October and January were months with the least 450 reductions due to high $\mathrm{VWC}$ and the presence of snow, respectively. January was the 
451 month with the lowest amount of heat loss for both the bare and green roofs. The large

452 reduction of heat loss in February may be attributed to the longer duration of snow cover

453 on the green roofs compared to bare roofs during thawing.

455 Our experimental observations are a result of roofs without insulation and ambient air 456 conditions on all sides of the heated box, including the bottom. Therefore, translations of 457 our results to an actual building are not direct and emphasis is placed rather on the plausible 458 causes discussed.

\subsection{Snow cover}

462 During consistent snow cover (approx. 20 days during the major freezing period in January 463 and into February), both the green and bare roofs experienced lower heat fluxes. A more 464 dramatic reduction in heat flux was exhibited by the bare roof compared to the green roof 465 for the duration of the snow period, except at the beginning and end of that period (Fig. 6). 466 At the beginning and end of the snow cover in January and during smaller snow events in 467 December, snow cover remained on the green roofs while it melted on the warmer surface 468 of the bare roof (Fig. 1). This lead to increased heat loss for the bare roof and increased 469 energy savings for the green roof. The nullifying effect that snow had on the relative green 470 roof benefits has been observed in other studies $[2,3,12,46]$. Despite the fact that snow 471 reduces the relative benefits of green roofs when covering both rooftops, these vegetated 472 roofs still benefited from greater snow depth, increased durations of snow cover, and 473 reduced temperature fluctuations compared to the bare roof surface. Therefore, according 474 to this study and [23], green roof designs that assist snow accumulation can also benefit 475 from the natural insulative properties of snow.

\section{Conclusion and future studies}

479 To obtain information on the energy efficiency of green roofs in Nordic climates, the 480 thermal behavior of the system and its components was assessed. A steady state analysis 481 on heat flux through the roofs provided thermal conductivity values along with their 
482 relationship to frost penetration. Each of the green roof layer k-values decreased during 483 freezing and a threshold VWC that determines whether vegetation and soil thermal 484 conductivity increases or decreases upon freezing is proposed. Above the critical VWC,

485 the layer's thermal conductivity value increases because of the large amount of highly 486 conductive ice. Below the critical VWC, the layer loses connectivity during freezing and 487 thermal conductivity is reduced. A substrate that drains optimally and holds moisture 488 content below the critical volume (15-20\%) can thus improve roof insulation during 489 freezing. Correspondingly, green roof equivalent thermal resistance increased along with 490 frost penetration and green roof heat flux remained lower than the bare roofs throughout 491 winter, except during snow cover when a similar heat flux was observed. Future studies 492 could validate our findings across various green roof soils with varying moisture contents.

494 Presented here are estimated heat flux and k-values determined from a one-dimensional 495 steady state analysis on experimental roofs. Further studies should model the dynamic 496 processes in which the effect of thermal mass, moisture and ice content, along with 497 convective and radiative heat transfer are considered in a transient conduction model. In 498 doing so k-values of greater reliability can be obtained and simulation programs (see e.g. 499 [8]) may be updated for Nordic climate analysis. Other considerations should include the 500 effects of material interfaces and three-dimensional heat transfer.

\section{Acknowledgements}

504 This project was performed in the "Fifth Dimension-Green Roofs in Urban Areas" 505 research group as part of the project ENSURE, Enhancing Sustainable Urban Development 506 through Ecosystem Services, funded by Helsinki University Centre for Environment, 507 HENVI. The study was also financially supported by the Helsinki-Uusimaa Region, Kone 508 Foundation and the Maj and Tor Nessling Foundation. The EU project UrbanEnviro 509 (European Social Fund) is also acknowledged for funding the Master's Degree Programme 510 in Multidisciplinary Studies on Urban Environmental Issues (MURE), which made this 511 study possible. 


\section{References}

515 [1] K.L. Getter, D.B. Rowe, The role of extensive green roofs in sustainable

516 development, HortScience. 41 (2006) 1276-1285.

517 [2] M. Zhao, J. Srebric, Assessment of green roof performance for sustainable

518 buildings under winter weather conditions, J. Cent. South Univ. Technol. (English

519 Ed. 19 (2012) 639-644. doi:10.1007/s11771-012-1050-1.

520 [3] U. Berardi, A. GhaffarianHoseini, A. GhaffarianHoseini, State-of-the-art analysis

521 of the environmental benefits of green roofs, Appl. Energy. 115 (2014) 411-428.

522 doi:10.1016/j.apenergy.2013.10.047.

523 [4] K.K.Y. Liu, Energy efficiency and environmental benefits of rooftop gardens,

$524 \quad$ Constr. Canada. 44 (2002) 17, 20-23.

525 [5] S.E. Ouldboukhitine, R. Belarbi, R. Djedjig, Characterization of green roof

526 components: Measurements of thermal and hydrological properties, Build.

527

528 [6] P. La Roche, U. Berardi, Comfort and energy savings with active green roofs,

529 Energy Build. 82 (2014) 492-504. doi:10.1016/j.enbuild.2014.07.055.

530 [7] S.S. Moody, D.J. Sailor, Development and application of a building energy

531 performance metric for green roof systems, Energy Build. 60 (2013) 262-269.

532 doi:10.1016/j.enbuild.2013.02.002.

533 [8] D.J. Sailor, A green roof model for building energy simulation programs, Energy Build. 40 (2008) 1466-1478. doi:10.1016/j.enbuild.2008.02.001.

535 [9] F. Ascione, N. Bianco, F. de’ Rossi, G. Turni, G.P. Vanoli, Green roofs in

536 European climates. Are effective solutions for the energy savings in airconditioning?, Appl. Energy. 104 (2013) 845-859.

538 doi:10.1016/j.apenergy.2012.11.068.

539 [10] E. Allen, I. Joseph, Fundamentals of Building Construction. Materials and Methods, 5th ed., John Wiley \& Sons, Inc., 2009.

541 doi:10.1017/CBO9781107415324.004.

542 [11] T. Theodosiou, Green Roofs in Buildings: Thermal and Environmental Behaviour, 543 Adv. Build. Energy Res. 3 (2009) 271-288. doi:10.3763/aber.2009.0311. 
544 [12] B. Bass, B. Baskaran, Evaluating Rooftop and Vertical Gardens as an Adaptation Strategy for Urban Areas, Natl. Res. Counc. Canada. (2001) 111. doi:NRCC46737.

547 [13] M. Squier, C.I. Davidson, Heat flux and seasonal thermal performance of an extensive green roof, Build. Environ. 107 (2016) 235-244. doi:10.1016/j.buildenv.2016.07.025.

[14] D.J. Sailor, T.B. Elley, M. Gibson, Exploring the building energy impacts of green roof design decisions - a modeling study of buildings in four distinct climates, J. Build. Phys. 35 (2012) 372-391. doi:10.1177/1744259111420076.

[15] H. Feng, K. Hewage, Energy saving performance of green vegetation on LEED certified buildings, Energy Build. 75 (2014) 281-289. doi:10.1016/j.enbuild.2013.10.039.

[16] S. Dinsdale, B. Pearen, C. Wilson, Feasibility Study for Green Roof Application on Queen's University Campus, Kingston, 2006.

[17] H.F. Castleton, V. Stovin, S.B.M. Beck, J.B. Davison, Green roofs; Building energy savings and the potential for retrofit, Energy Build. 42 (2010) 1582-1591. doi:10.1016/j.enbuild.2010.05.004.

[18] K.K.Y. Liu, J. Minor, Performance Evaluation of an Extensive Green Roof, Green. Rooftops Sustain. Communities. (2005) 1-11. doi:10.1109/ICEOE.2011.6013104.

[19] S.K. Weiler, K. Scholz-Barth, Green roof systems : a guide to the planning, design, and construction of landscapes over structure, 2009. doi:10.1017/CBO9781107415324.004.

566 [20] C.Y. Jim, Passive warming of indoor space induced by tropical green roof in winter, Energy. 68 (2014) 272-282. doi:10.1016/j.energy.2014.02.105.

568 [21] C.Y. Jim, S.W. Tsang, Biophysical properties and thermal performance of an 569 intensive green roof, Build. Environ. 46 (2011) 1263-1274. doi:10.1016/j.buildenv.2010.12.013. green roofs on building energy performance, Renew. Energy. 43 (2012) 157-164.

574 [23] J.T. Lundholm, B.M. Weddle, J.S. Macivor, Snow depth and vegetation type affect 
green roof thermal performance in winter, Energy Build. 84 (2014) 299-307. doi:10.1016/j.enbuild.2014.07.093.

[24] R.K. Sutton, Green Roof Ecosystems, Series Vol, Springer International Publishing, Switzerland, 2015. doi:10.1007/978-3-319-14983-7.

[25] R.W.F. Cameron, J. Taylor, M. Emmett, A Hedera green facade - Energy performance and saving under different maritime-temperate, winter weather conditions, Build. Environ. 92 (2015) 111-121. doi:10.1016/j.buildenv.2015.04.011.

[26] M.J. Moran, H.N. Shapiro, Fundamentals of Engineering Thermodynamics, Nature. 181 (2006) 1-847. doi:10.1038/1811028b0. D.J. Sailor, D. Hutchinson, L. Bokovoy, Thermal property measurements for ecoroof soils common in the western U.S., Energy Build. 40 (2008) 1246-1251. doi:10.1016/j.enbuild.2007.11.004.

[28] O.T. Farouki, Thermal properties of soils, U.S. Army Cold Regions Research and Engineering Laboratory, Hanover, New Hampshire, 1981.

[29] P.P. Overduin, D.L. Kane, W.K.P. van Loon, Measuring thermal conductivity in freezing and thawing soil using the soil temperature response to heating, Cold Reg. Sci. Technol. 45 (2006) 8-22. doi:10.1016/j.coldregions.2005.12.003.

[30] S. Seigo, Temperature Dependence of Thermal Conductivity of Frozen Soil,

595 [31] Finnish Meteorological Institiute, Finnish Meteorological Institute, Snow Stat. (2013). http://ilmatieteenlaitos.fi/lumitilastot (in Finnish) (accessed January 1,

598 [32] Veg Tech, Vegetationsteknik. Grönare byggande för framtidens städer. (A brochure in Swedish), (2014).

600 [33] Decagon Incorporated, 5TM Water Content and Temperature Sensors, Tech. Man. (2014). http://www.decagon.com/.

[34] W.M. Rohsenow, J.P. Hartnett, Y.I. Cho, Handbook of Heat Transfer, 3rd ed, The

603 McGraw-Hill Companies, New York, New York, 1998. doi:10.1016/00179310(64)90164-4.

605 [35] N. Bénichou, M.A. Sultan, Fire resistance performance of lightweight wood- 
framed assemblies, Fire Technol. 36 (2000) 184-219. doi:10.1023/A:1015414827695.

[36] I. Valovirta, J. Vinha, Water vapor permeability and thermal conductivity as a function of temperature and relative humidity, Perform. Exter. Envel. Whole Build. IX Conf. Proc. (2004).

611 [37] Nophadrain BV, Technical Data Sheet 0.7, ND drainage composites, 2013.

612 http://esha.bg/docs/0.7TechnicalDataSheetNDDrainageComposites.pdf.

613 [38] E. Penner, G.H. Johnston, L.E. Goodrich, Thermal conductivity laboratory studies

[39] R. Djedjig, S.-E. Ouldboukhitine, R. Belarbi, E. Bozonnet, Development and validation of a coupled heat and mass transfer model for green roofs, Int. Commun. Heat Mass Transf. 39 (2012) 752-761. doi:10.1016/j.icheatmasstransfer.2012.03.024.

[40] E. Penner, Thermal conductivity of frozen soils, Can. J. Earth Sci. 7 (1970) 982987. doi:10.1139/e70-091.

[41] X.-F. Pang, Water: Molecular Structure and Properties, World Scientific, 2014.

[42] P. Hoekstra, The physics and chemistry of frozen soils, in: Highw. Res. Board Spec. Rep., Washington DC, 1969: pp. 78-90.

[43] G. Bovesecchi, P. Coppa, Basic problems in thermal-conductivity measurements of soils, Int. J. Thermophys. 34 (2013) 1962-1974. doi:10.1007/s10765-013-15032.

[44] B. Zhang, C. Han, X. (Bill) Yu, A non-destructive method to measure the thermal properties of frozen soils during phase transition, J. Rock Mech. Geotech. Eng. 7 (2015) 155-162. doi:10.1016/j.jrmge.2015.03.005.

[45] G. Li, Q. Yu, W. Ma, Y. Mu, X. Li, Z. Chen, Laboratory testing on heat transfer of frozen soil blocks used as backfills of pile foundation in permafrost along QinghaiTibet electrical transmission line, Arab. J. Geosci. 8 (2015) 2527-2535. doi:10.1007/s12517-014-1432-9.

[46] M. Zhao, J. Srebric, R.D. Berghage, K.A. Dressler, Accumulated snow layer influence on the heat transfer process through green roof assemblies, Build. 
